\title{
Cicatrizadores personalizados: relato de caso
}

\author{
Customized healing abutments: case report
}

Fábio Assada ${ }^{1, a, b}$, Rafael dos Santos Silva ${ }^{2, c}$, Rodrigo Lorenzi Poluha ${ }^{3, a}$.

\section{RESUMO}

Quando feita a instalação de um implante imediato pode se optar entre a instalação de uma coroa provisória clínica, um cicatrizador ou pode se optar pelo fechamento do implante para um tratamento em duas etapas cirúrgicas. O uso de cicatrizadores personalizados sela os implantes e leva a uma cicatrização individualizada, que favorece a confecção das coroas subsequentes. O presente trabalho objetiva relatar um caso clínico envolvendo um implante imediato e a instalação de um cicatrizador personalizado, demonstrando os resultados e a importância de conhecimento dessa técnica pelo cirurgião-dentista.

\section{PALAVRAS-CHAVE: Unitário sobre implante; contorno gingival; cicatrizador personalizado.}

\section{SUMMARY}

When installing an immediate implant, you can choose between installing a temporary clinical crown, healing abutments, or to close the implant for a two-step surgical treatment. The use of customized healing abutments seals the implants and leads to individualized healing, which favors the creation of subsequent crowns. The present study aims to report a clinical case involving an immediate implant and the installation of customized healing abutments, demonstrating the results and the importance of knowledge of this technique by the dentist.

KEY WORDS: Single-tooth implant restoration; Gengival contour; Customized healing abutments.

Centro Educacional Dental Press. Maringá, PR, Brasil.

Departamento de Odontologia, Universidade Estadual de Maringá. Maringá,PR, Brasil.

Departamento de Prótese Dentária, Faculdade de Odontologia de Bauru, Universidade de São Paulo-USP. Bauru, São Paulo, Brasil.

Cirurgião Dentista.

Especialista em Implantodontia.

Professor 


\section{INTRODUÇÃO}

Os implantes dentários são indicados para pacientes com perdas dentárias ou para substituição de um dente que foi traumatizado ou que estejam em mau estado de conservação. Nessa última situação, o dente que não apresenta outra possibilidade de tratamento é extraído e substituído imediatamente por um implante (1). No Brasil, segundo levantamento da Associação Brasileira da Indústria Médica, Odontológico e Hospitalar (Abimo), cerca de 800 mil implantes são colocados por ano no país (1).

Os implantes podem ser classificados de acordo com o tempo de sua instalação. Os implantes tardios são realizados quando o osso está completamente cicatrizado, ou seja, após 3 meses após a extração (2). Os implantes precoces ocorrem entre um mês de extração, quando a gengiva já cicatrizou e menos do que três meses, quando o osso não cicatrizou completamente. A técnica mais rápida existente é a de carga imediata, em que a colocação do novo dente pode ser feita em até 72 horas após a colocação do parafuso de titânio. O paciente precisa ter resistência óssea no momento da instalação. Caso ele for adequado, pode ser feita a carga imediata. Se não for, deve-se seguir o protocolo tradicional, de esperar o processo de osseointegração (2).

Quando feita a instalação de um implante imediato pode se optar entre a instalação de uma coroa provisória clínica, um cicatrizador ou pode se optar pelo fechamento do implante para um tratamento em duas etapas cirúrgicas (3). Os implantes recebem parafusos ou cicatrizadores padronizados e, mantidos submersos ou expostos, não previnem a descaracterização do contorno cervical das coroas dentárias naturais (3). O uso de cicatrizadores personalizados sela os implantes e leva a uma cicatrização individualizada, que favorece a confecção das coroas subsequentes (4). O resultado clínico é mais estável, com mais conforto para o paciente, estabilidade dos tecidos peri-implantares e prevenção de traumas sobre esta área delicada (3).

O presente trabalho objetiva relatar um caso clínico envolvendo um implante imediato e a instalação de um cicatrizador personalizado, demonstrando os resultados e a importância de conhecimento dessa técnica pelo cirurgião-dentista

\section{Relato de caso}

A paciente ERL, gênero feminino, 28 anos, procurou atendimento relatando dor na região anterior superior, com histórico de trauma prévio durante a mastigação. $\mathrm{Na}$ avaliação da paciente, o dente 21 , aonde havia uma coroa cerâmica instalada com núcleo metálico, apresentava uma fratura obliqua, gengiva edemaciada, com sinais clínicos de infecção na parede vestibular do alvéolo (figura 1 e figura 2). O plano de tratamento incluiu a indicação de exodontia do dente 21 , seguida de um implante imediato (Straumann ${ }^{\circledR}$ Bone Level SLActive) associado a um cicatrizador personalizado para manter a caracterização do contorno gengival do elemento.

Foi realizado uma moldagem prévia a cirurgia, e no modelo de trabalho, foi realizado um desgaste com brocas carbide esféricas seguindo o limite da

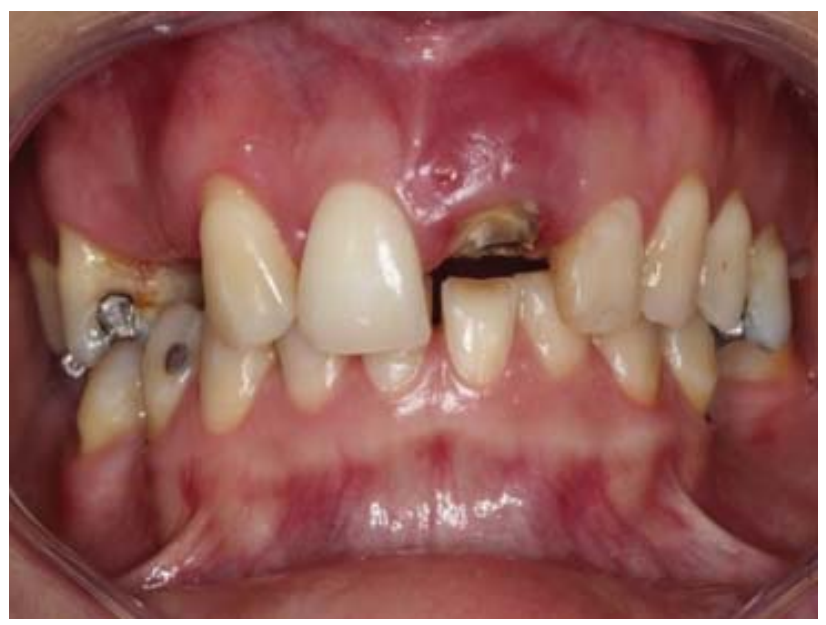

Figura 1. Aspecto inicial, vista frontal.

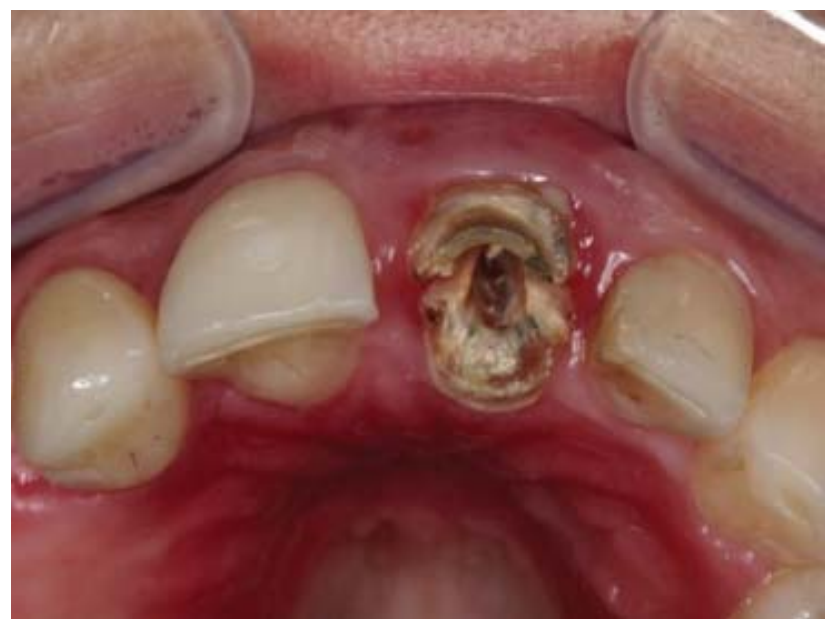

Figura 2. Aspecto inicial, vista oclusal. 


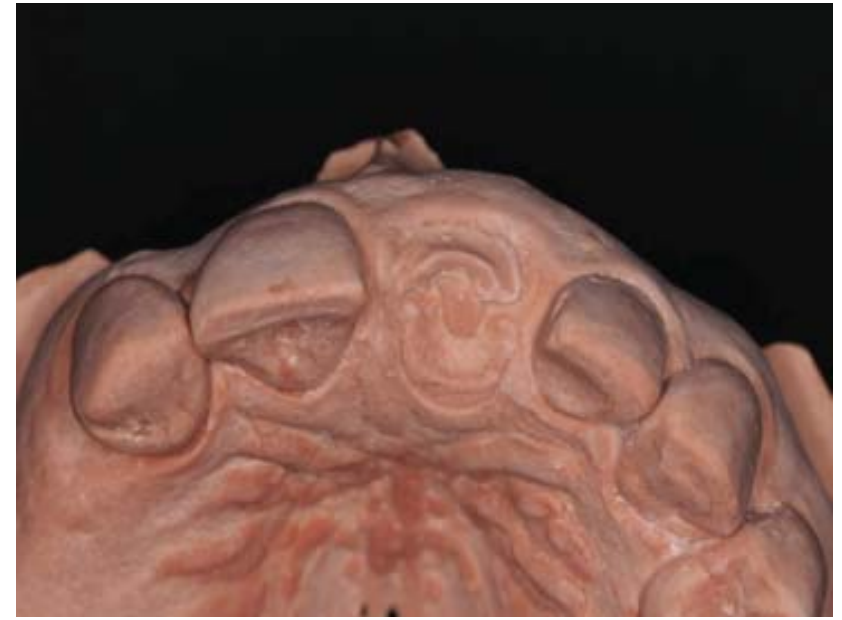

Figura 3. Gesso, aspecto inicial, vista oclusal.

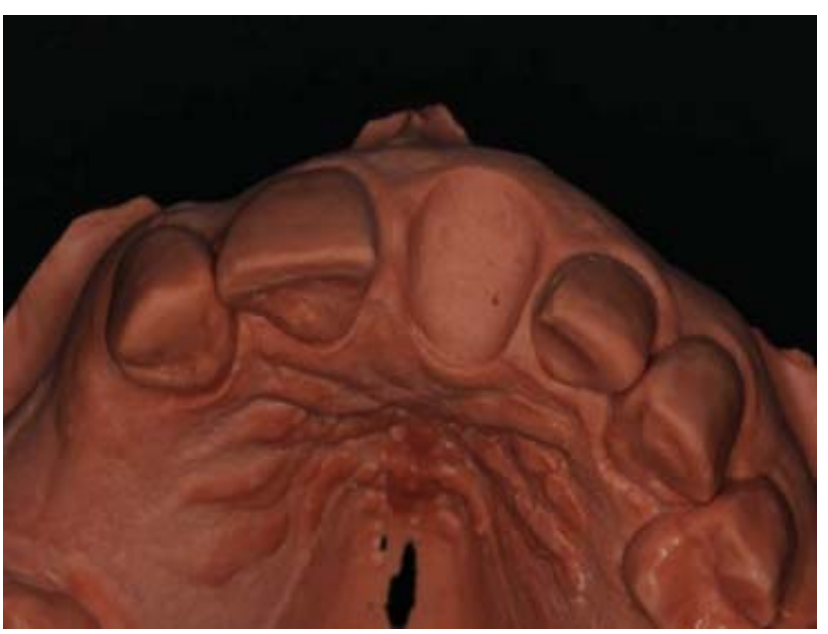

Figura 4. Gesso, área preparada, vista oclusal.

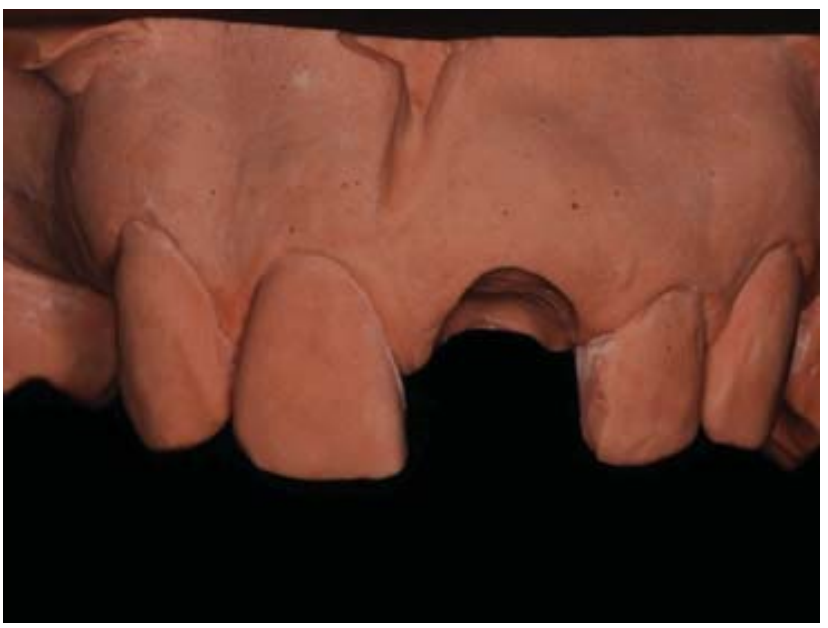

Figura 5. Gesso, área preparada, vista frontal.

margem gengival com aproximadamente $2 \mathrm{~mm}$ de profundidade. A concavidade foi isolada e preenchida com resina flow $\left(Z 350,3 \mathrm{M}^{\circledR}\right)$ até o nível da marcação cervical, respeitando uma área central mais palatina para acilitar a posterior união com o cilindro

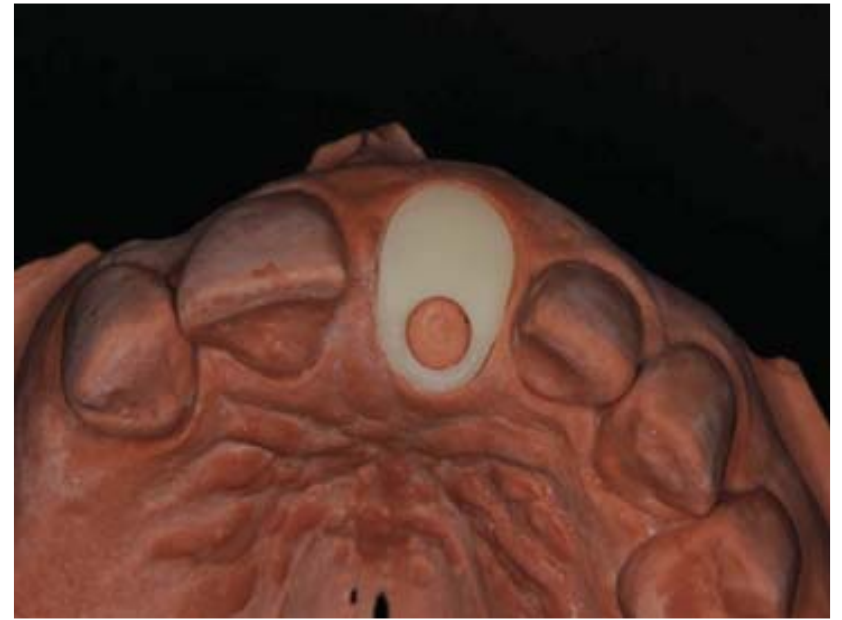

Figura 6. Tampão de resina confeccionado.

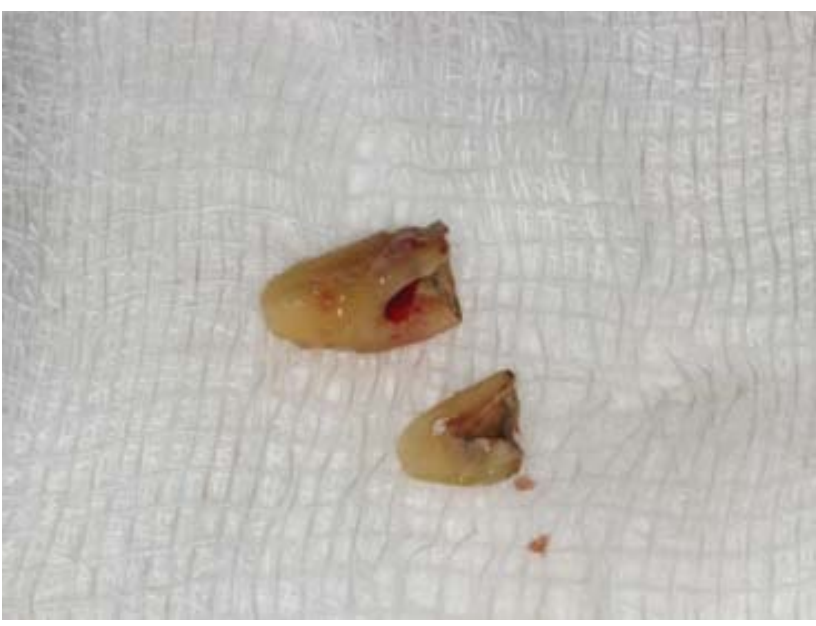

Figura 7. Elemento 21 extraído.

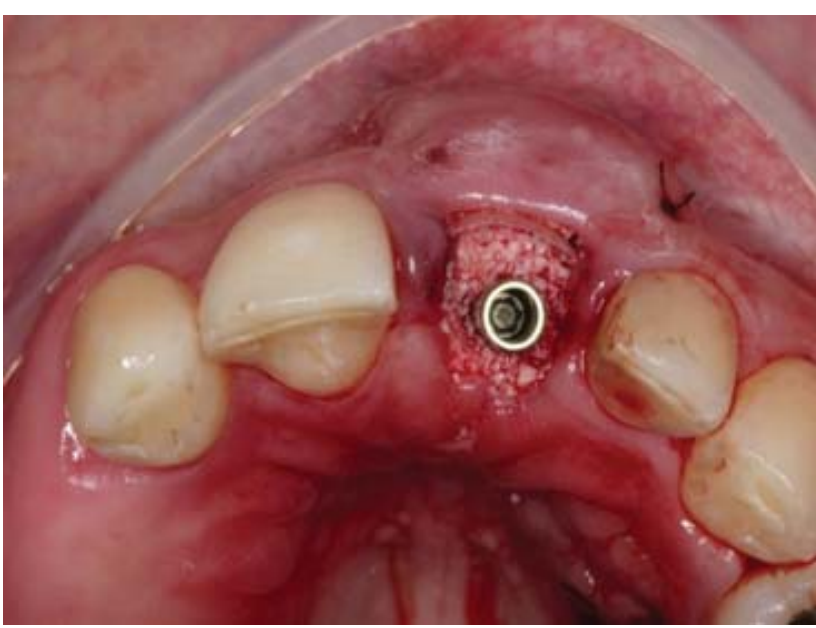

Figura 8. Implante instalado.

provisório. Em seguida, realizam-se o acabamento, o polimento e a desinfecção da peça, deixando-a pronta para o uso cirúrgico (figura 3, figura 4, figura 5 e figura 6). 
Simultaneamente, foi realizada a exodontia do elemento 21, seguida da instalação do implante com toque final de $30 \mathrm{~N}$. O espaço alveolar remanescente foi preenchido primeiro com o enxerto de conjuntivo associado a uma membrana de colágeno reabsorvível (GenDerm - Baumer), juntamente com material de substituição óssea (Geistlich Bio-Oss, Geistlich Pharma) (figura 7 e figura 8).

Finalizado toda a parte cirúrgica foi feito o posicionamento de um cilindro provisório e da tampa de cobertura que havia sido confeccionado no gesso e feita a união com resina tipo flow, seguindo do acabamento e polimento fora da boca. Uma vez pronto o cicatrizador personalizado, este foi instalado com o torque de $15 \mathrm{~N}$ e uma prótese parcial removível provisória foi instalada (figura 9, figura 10, figura 11, figura 12, figura 13 e figura 14).

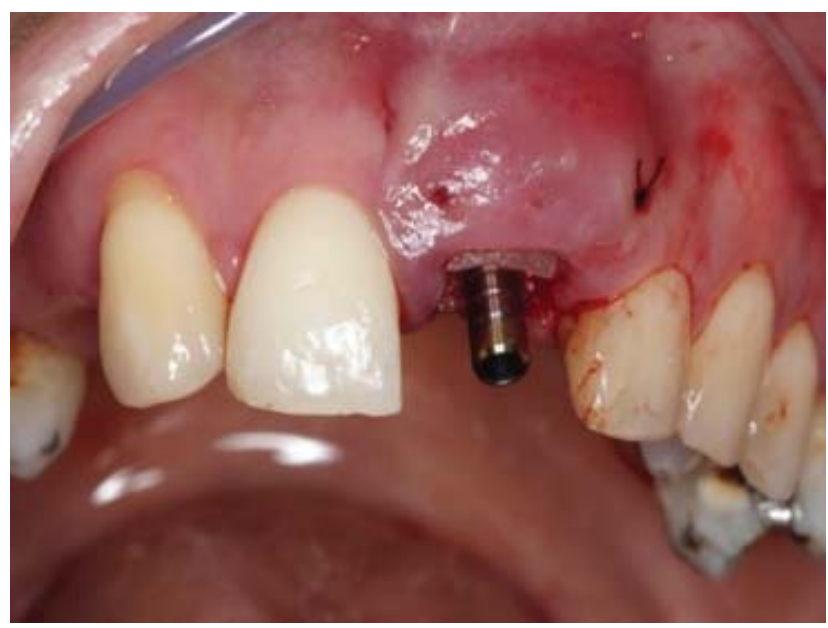

Figura 9. Cilindro provisório posicionado.

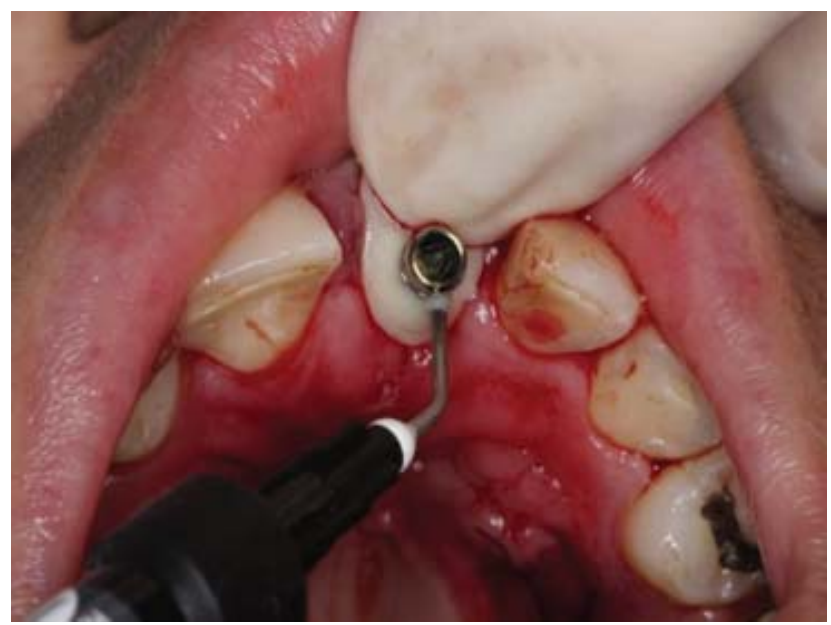

Figura 10. União do tampão de resina com o cilindro provisório posicionado.

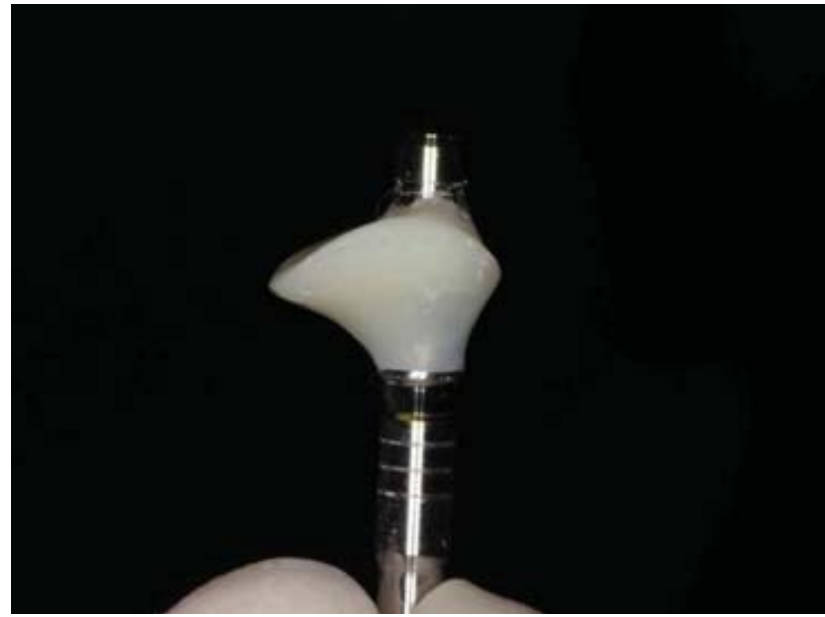

Figura 11. Cicatrizador personalizado confeccionado, vista laretal.

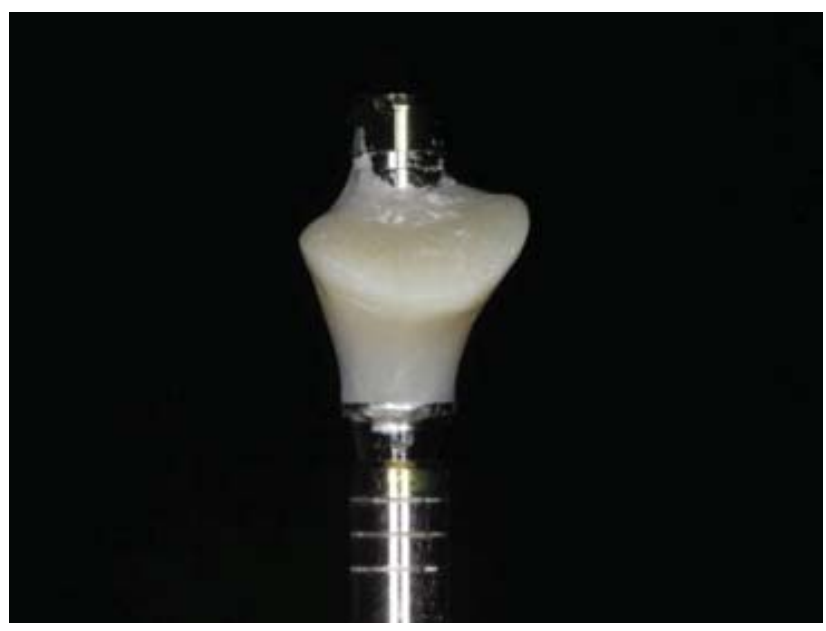

Figura 12. Cicatrizador personalizado confeccionado, vista frontal.

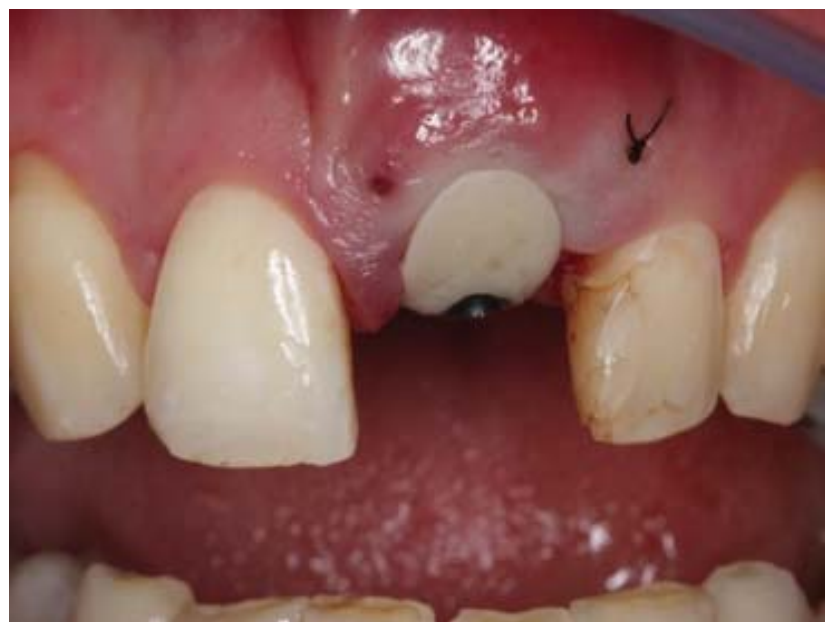

Figura 13. Cicatrizador personalizado instalado, vista frontal. 


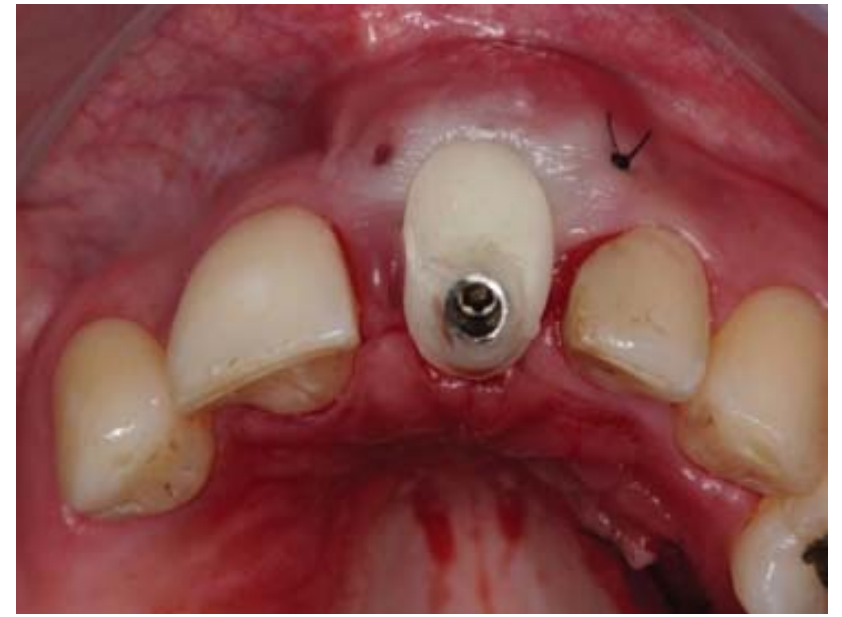

Figura 14. Cicatrizador personalizado instalado, vista oclusal.

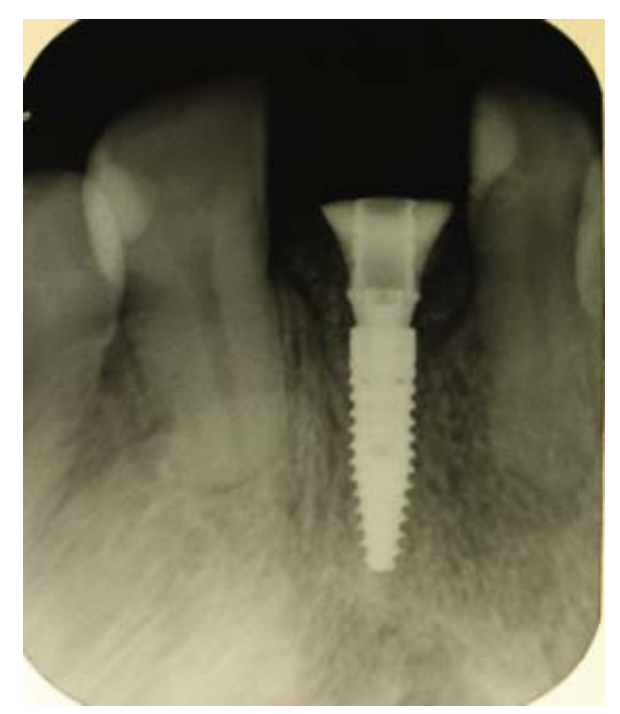

Figura 15. RX após instalação do cicatrizador personalizado

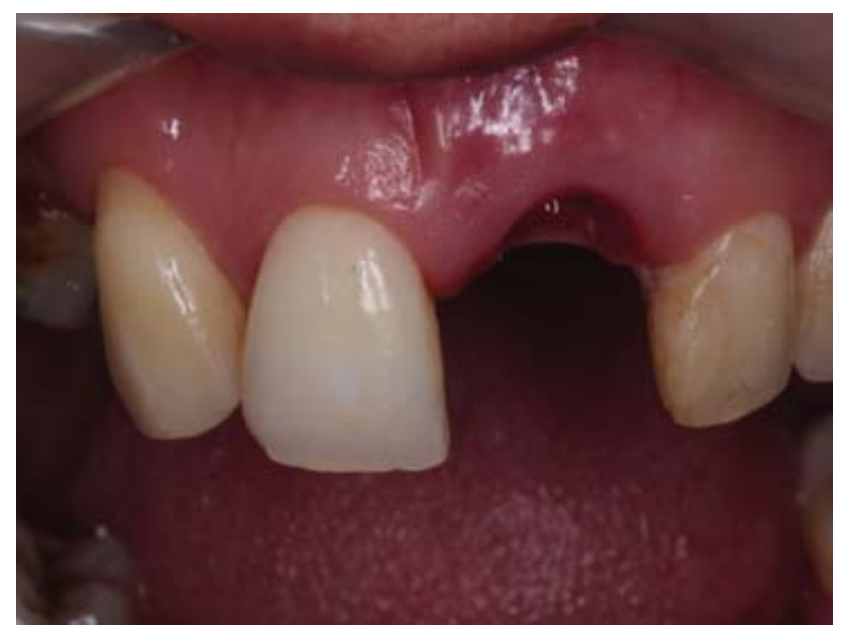

Figura 16. Aspecto após 4 meses, vista frontal.

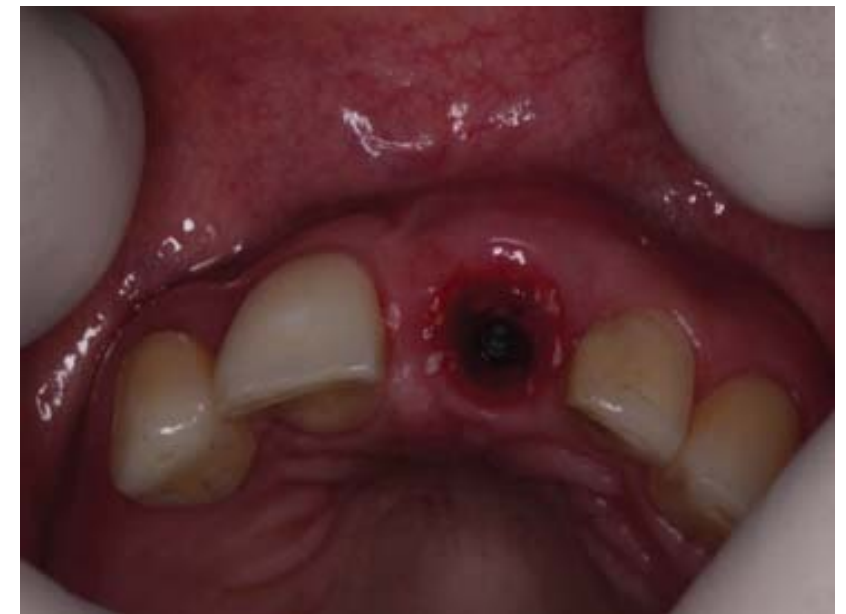

Figura 17. Aspecto após 4 meses, vista oclusal.

A paciente retornou após 4 meses e foi constatado um resultado satisfatório da cicatrização tecidual e a manutenção da arquitetura gengival (figura 15 e figura 16).

\section{DISCUSSÃO}

No caso clínico apresentado, observamos a necessidade de conhecimento de técnicas de periodontia e implantodontia para se obter uma região com uma estética favorável para a instalação de uma coroa com um perfil protético adequado. A correta estética da reabilitação implanto suportada está aliada a correta manipulação e condicionado do tecido gengiva e o momento correto em que esse procedimento é realizado (5). Embora um bom travamento dos implantes possibilite a realização de carga imediata, alguns cuidados como evitar excesso de carga oclusal na fase inicial devem ser respeitados (3). No presente caso, caso se tivesse realizado uma coroa provisória implanto suportada, o extenso overbite inevitavelmente promoveria uma carga oclusal excessiva tanto na máxima intercuspidação, quanto nas guias de desoclusão sobre um implante ainda em fase de cicatrização, podendo comprometer o sucesso da reabilitação.

Idealmente os cicatrizadores devem ter as conformações de largura próximo ao do dente que devem reestabelecer (6). No entanto, os cicatrizadores padronizados falham nessa relação e podem tornar o perfil de tecido gengival circundante desfavorável, exigindo um condicionamento adicional, que usualmente exige um maior tempo de tratamento 
(7). No presente caso, se houvesse instalado a utilização de um cicatrizador padronizado, haveria o risco de ocorrer perda do contorno gengival do elemento 21. O uso de cicatrizador personalizado é uma boa alternativa para a conformação de perfis de emergência gengival, permitindo inclusive pular a fase de coroa provisória sobre implante, reduzindo significativamente o custo de um tratamento e otimizando a modelagem dos tecidos (8) Além disso, os cicatrizadores personalizados protegem os enxertos e todo o leito cirúrgico, resultando no aumento do volume ósseo e dos tecidos moles (9). Como desvantagem, o cicatrizador personalizado não possibilita sua reutilização, sendo descartável ou necessário modificações para outros casos.

Pode-se concluir que cicatrizadores personalizados são uma excelente opção de tratamento em diversos casos. Sua aplicabilidade depende do conhecimento do cirurgião sobre as indicações, técnicas e experiência. A confecção de cicatrizadores personalizados pode ser fundamental para o sucesso do tratamento clínico ajudando em muitos casos a estética função e manutenção do implante.

\section{Autor correspondente:}

Rodrigo Lorenzi Poluha

E-mail: rodrigopoluha@gmail.com

\section{REFERÊNCIAS}

1. Conselho Federal de Odontologia. Cresce o número de implantes dentários no Brasil. Brasília: Conselho Federal de Odontologia; 2014. (Acesso em: 1 dez. 2018) Disponível m: http://cfo.org.br/website/cresce-onumero-de-implantes-dentarios-no-brasil/.

2. Buser D, Chappuis V, Belser UC, Chen S. Implant placement post extraction in esthetic single tooth sites: when immediate, when early, when late? Periodontol2000; 2017;73(1):84-102.

3. Telles D. Próteses fixas sobre implantes. São Paulo: Quintessence; 2014.

4. Vasconcelos LW, Hiramatsu DA, Paleckis L, Francischone CE, Vasconcelos RCB. Cicatrizadores personalizados sobre implantes imediatos em áreas de molares: preservando a arquitetura original dos tecidos. Int J Oral Maxillofac Implants. 2017;2:1059-1065.

5. Kadkhodazadeh M, Amid R, Kermani ME, Mirakhori M, Hosseinpour S. Timing of soft tissue management around dental implants: a suggested protocol. Gen Dent. 2017;65(3):50-56

6. Proussaefs P. Immediate provisionalization with a CAD/CAM interim abutment and crown: a guided soft tissue healing technique. J Prosthet Dent. 2015;113:915.

7. Bhola M, Neely AL, Kolhatkar S. Immediate implant placement: clinical decisions, advantages, and disadvantages. J Prosthodont. 2008;17: 576-81

8. Huaytalla L, Matta C. Cicatrizadores personalizados: Una opción para conformación del perfil de emergencia en próteses sobre implantes posteriores. Rev Estomatol Herediana. 2018;28(4):279-86.

9. Stumpel LJ, Wadhwani C. A Customized healing abutment for immediate and delayed implant cases. Compend Contin Educ Dent. 2017;38(10):672-678.

Recibido: 04-04-2018

Aceptado: 06-08-2019 